\title{
Immediate breast reconstruction with a 'modified fleur-de-lis' abdominal-free flap in a patient with previous abdominal surgery
}

\author{
Manuel Robustillo, Luis Parra Pont, Georgios Pafitanis', Pedro Ciudad², Daniel Grandes, \\ Israel Iglesias \\ Department of Plastic and Reconstructive Surgery, Hospital 12 de Octubre, Madrid, Spain, ${ }^{1}$ Department of Plastic and \\ Reconstructive Surgery Queen Mary University of London, The Royal London Hospital, Barts Health NHS Trust, London, \\ United Kingdom, '2Department of Plastic and Reconstructive Surgery, China Medical University Hospital, Taichung, Taiwan
}

Address for correspondence: Dr. Manuel Robustillo, Hospital 12 de Octubre, Avenida de Andalucia S/N, 28041, Madrid, Spain. E-mail: manu_robus24@hotmail.com

\section{ABSTRACT}

DIEP flap has become the gold standard method for patients undergoing autologous breast reconstruction; however, previous surgery or scars in the abdominal area have been considered a relative contraindication for the use of abdominal tissue. Longitudinal midline abdominal scars may be specially problematic because of the poor midline crossover of blood and the high risk of necrosis of the distal flap. Patients with small breast may be easily reconstructed with hemi-DIEP flap; however, patients with large breast need more tissue available. Our aim is to report a modification of a 'fleur-de-lis pattern' for a breast reconstruction in a patient with previous abdominal surgery and large breast. The post-operative course was uneventful, flap did not show blood supply compromise, volume and symmetry are preserved after 6 months post-operative and donor site morbidity has not been observed. This modification may be very useful to avoid complications related to poor blood supply associated with scar tissues. Careful pre-operative planning and the transfer of only well-vascularised tissue are essential for a successful reconstruction.

\section{KEY WORDS}

Abdominal scars; breast reconstruction; fleur-de-lis; modified DIEP

\section{INTRODUCTION}

The deep inferior epigastric artery perforator free flap is widely accepted as the gold standard method for breast reconstruction as it combines

\begin{tabular}{|l|l|}
\hline \multicolumn{2}{|c|}{ Access this article online } \\
\hline Quick Response Code: & Website: \\
\hline & www.ijps.org \\
\cline { 2 - 2 } & DoI: \\
\hline
\end{tabular}

good donor site aesthetic outcomes with low morbidity and autologous tissue characteristics with optimal long-term cosmetic results. ${ }^{[1]}$

This is an open access journal, and articles are distributed under the terms of the Creative Commons Attribution-NonCommercial-ShareAlike 4.0 License, which allows others to remix, tweak, and build upon the work non-commercially, as long as appropriate credit is given and the new creations are licensed under the identical terms.

For reprints contact: reprints@medknow.com

How to cite this article: Robustillo M, Pont LP, Pafitanis G, Ciudad P,
Grandes D, Iglesias I. Immediate breast reconstruction with a
'modified fleur-de-lis' abdominal-free flap in a patient with previous
abdominal surgery. Indian J Plast Surg 2018;51:89-92.

How to cite this article: Robustillo M, Pont LP, Pafitanis G, Ciudad P, 'modified fleur-c abdominal surgery. Indian J Plast Surg 2018;51:89-92. 
Previous abdominal scars have been traditionally considered a relative contraindication for autologous breast reconstruction with free abdominal flap because of decreased perfusion and venous congestion with the associated fat and marginal skin necrosis. ${ }^{[2-4]}$

Autologous breast reconstruction remains a challenge in patients with previous abdominal scars. Pre-operative imaging and intra-operative perfusion studies may offer established assessment tools to evaluate blood supply of the free tissue transfer; however, there is a lack of evidence supporting that adverse outcomes in this specific cohort of patient are able to be standardised and avoided. ${ }^{[5]}$ We report a case of a large breasted female patient with previous vertical midline and lower Pfannenstiel scars, who underwent successful immediate autologous breast reconstruction with a modified fleur-de-lis abdominal free flap.

\section{CASE REPORT}

A 45-year-female presented with a suspicious radiological routine screening test (BI-RADS 5) to the outpatient breast cancer clinic. Consent form was obtained.

A mass was identified at the right superior-lateral breast $(1.7 \mathrm{~cm} \times 2.2 \mathrm{~cm})$ with associated right lymphadenopathy $(1.4 \mathrm{~cm})$, without distal metastasis detected on computerised tomography (CT) (T2N1M0). On the histopathologic study of the right breast specimen, a high-grade carcinoma was evidenced. Neoadjuvant chemotherapy was commenced, and a follow-up magnetic resonance imaging revealed a significant downgrading of the primary lesion with decreased size but persistence of the axillary lymphadenopathy. The decision to proceed with total mastectomy with axillary lymph node clearance and immediate breast reconstruction was decided through a multidisciplinary team approach.

During pre-operative assessment, the physical examination revealed two previous abdominal scars: a midlinelaparotomy incision from the xiphisternum to the pubis symphysis and a Pfannenstiel incision from a previous caesarean section. The patient had body mass index of 38, however, without any other co-morbidities. Patients' consultation resulted in the decision to proceed with skin-sparing mastectomy, axillary lymph node clearance and immediate autologous breast reconstruction with free abdominal flap with contralateral symmetrisation breast reduction.
The patient underwent pre- and intra-operative handheld Doppler mapping to identify the location of perforators. The patient's body habitus required further pre-operative planning and design of a modified 'fleur-de-lis' abdominal flap, to allow large amount of tissue transfer along with improved donor site aesthetic outcomes [Figure 1].

Three perforators were identified from the left deep inferior epigastric artery system. The presence of the vertical midline laparotomy scar proclaimed the risk of low perfusion of the contralateral abdominal flap area. This suspicion was confirmed intra-operatively during completion of the perforator dissection and clamp testing of dominance. The left-sided fleur-de-lis flap was not perfused and therefore was not transferred to the breast. Perfusion of this side was checked with INVOS ${ }^{\mathrm{TM}}$ system, showing low oxygen saturation, and deoxygenated bleeding was observed after incisions. Fluorescein was not used.

The internal mammary artery vessels were prepared as the recipient vessels in a standard fashion, using the third intercostal cartilage space. The right mastectomy defect was reconstructed, and the flap was anastomosed in and end-to-end fashion. During flap inset, a large area of de-epithelisation allowed good aesthetic results and enabled a small skin monitoring paddle to cover the skin envelope defect. A contralateral wise pattern breast reduction achieved symmetrisation of the right breast.

There were no intra- and post-operative complications. Breast, flap and donor sites' healing achieved without partial necrosis getting a well-rounded free flap reconstructed breast and a symmetric reduced contralateral side. The patient was discharged on the

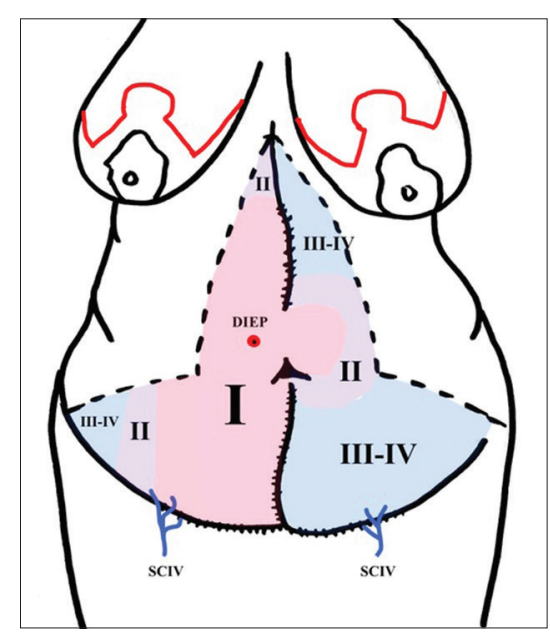

Figure 1: Modified fleur-de-lis design based on the patient's abdominal scars, reduction pattern in both breasts and abdominal zones of perfusion 
$5^{\text {th }}$ post-operative day without any concerns. A secondary procedure was scheduled for nipple reconstruction.

\section{DISCUSSION}

Deep inferior epigastric artery-based abdominal free flap is becoming the gold standard option for breast reconstruction. Immediate autologous breast reconstruction offers optimal cosmetic long-term outcomes and high rates of quality of life. ${ }^{[1]}$ The presence of previous abdominal scars presents a challenge and a relative contraindication as it can affect the flap survival due to irregular perfusion patterns. ${ }^{\left[{ }^{[6]}\right.}$

There is a lack of evidence concerning the regeneration and neovascularisation of the superficial or deep inferior epigastric vascular systems of the abdominal wall following abdominal procedures. Han et al. demonstrated on animal models that an increase in size and density of the subdermal plexus is observed, similarly to the delay phenomenon, in the areas surrounding a healing scar. $^{[7]}$ However, another study contradicted that previous existent vascular pattern was able to be regenerated, showing the absence of staining infused through the surrounding vessel and surpassing mature scars in cadaveric dissections. ${ }^{[8]}$ Sano et al. also reported similar observation in the rat model, when contralateral hemi-abdominal flaps failed neovascularisation across the midline scar. ${ }^{[9]}$

Midline abdominal scars are decreasing as the rates of exploratory laparotomy have been largely replaced from laparoscopic procedures; however, Pfannenstiel abdominal scars are very commonly encountered as the rates of caesarean sections increased. ${ }^{[10]}$ A long midline incision from the xiphoid process to the pubis symphysis presents a major challenge in pre-operative decision-making for breast reconstruction, as it disrupts the vascular connections between hemi-abdominal flaps. ${ }^{[11]}$

Recent literature has reported an increase in the prevalence of complications in cases undergoing DIEP flap with the presence of abdominal scars. ${ }^{[2,12]}$ Chang et al. reported a case of partial flap loss in a patient with midline abdominal scar which during surgical re-exploration arterial and venous anastomosis were revealed patented, findings of which coincide with this concept. ${ }^{[3]}$
Several modifications in abdominal flap designs have been described to enable higher perfusion rates in scar areas and attempt to reduce associated complications..$^{[2,4,12]}$ Hsieh et al. allowed robust perfusion across flaps with midline abdominal scars with a crossover anastomosis and demonstrated good post-operative outcomes. ${ }^{[5]}$ Conservative approach in the presence of abdominal scars is allowed when patients require small tissue; ${ }^{[6]}$ however, reconstruction of large breast may be hindered by the amount of tissue available; to overcome this situation, new flap designs must be developed to get the finest results possible. ${ }^{[2,4]}$ Santanelli et al. proposed the use of vertical DIEP (VDIEP) flap in patients affected by midline scars and large breast volume in whom one side of the abdomen is not enough for the reconstruction. ${ }^{[13]}$

In our patient, a fleur-de-lis design was chosen to achieve as much tissue as possible and improve the aesthetic result of the previous scars, after noticing patient's complaint of her abdominal aesthetics and her desire of large breast volume [Figures 2 and 3]. This design, therefore, fulfilled the two requisites providing high-quality tissue avoiding another donor area with just one incision in abdominal fascia limiting the morbidity in the donor site and making the procedure faster. In addition, the classic transverse DIEP flap, as postulated by Dinner et al., captures four vascular zones with different perfusion gradients, ${ }^{[8]}$ while the VDIEP only captures two; thus, perfusion of the flap should be guaranteed.

In our case, after harvesting the flap, one side of the fleur-de-lis was clinically low perfused, which was expected; however, the lack of perfusion may not be

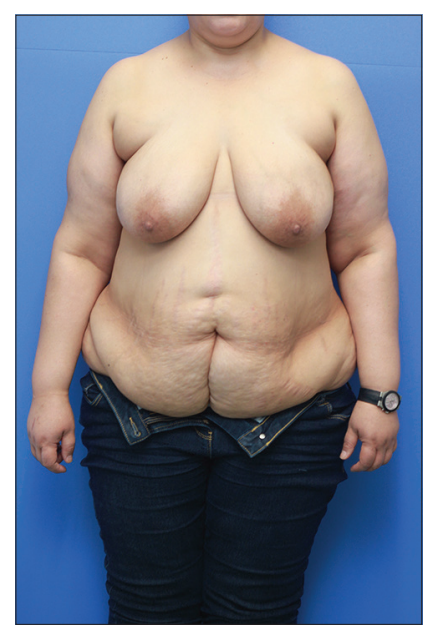

Figure 2: High body mass index patient, large breast volume and previous abdominal scars before breast reconstruction with autologous abdominal tissue 


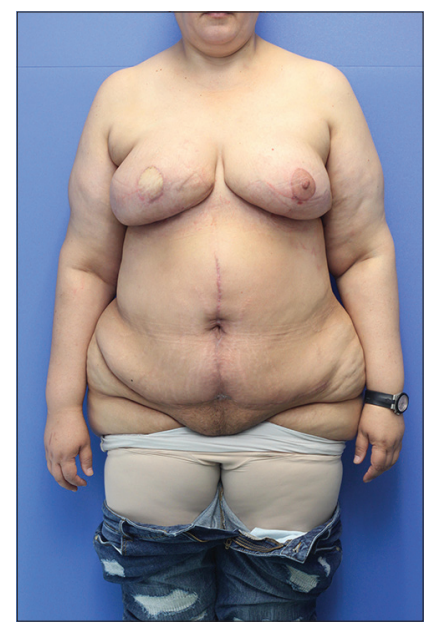

Figure 3: Outcome after 6 months. Reconstructed breast remains similar in shape and volume compared to the other side

evident intra-operatively, and problems may arise on the immediate post-operative period..$^{[12]}$

Many authors recommended pre-operative imaging in any patientwithabdominalscars; ${ }^{[10]}$ however, in ourexperience, preoperative angio-CT may be recommended but not essential. Clinical expertise, intra-operative findings and evaluation of the flap after perforator dissection are thus of great importance. The breast volume required and the amount of tissue available at donor site can guide our decisions for planning autologous reconstruction using DIEP flap and contralateral symmetrisation.

This case shows the possibility of reconstruction with multiple abdominal scars and achieves a symmetric outcome in patients with large breast volume. Careful pre-operative planning and the transfer of only well-vascularised tissue are essential for a successful reconstruction.

\section{CONCLUSION}

Patients with multiple abdominal scars and large-volume breast can be reconstructed safely with minimal technical modifications in DIEP flaps' design and contralateral breast reduction.

Precise analysis of each individual case is imperative to overcome donor site limitations and achieve best surgical outcomes.

\section{Declaration of patient consent}

The authors certify that they have obtained all appropriate patient consent forms. In the form the patient(s) has/have given his/her/their consent for his/her/their images and other clinical information to be reported in the journal. The patients understand that their names and initials will not be published and due efforts will be made to conceal their identity, but anonymity cannot be guaranteed.

\section{Financial support and sponsorship}

The authors have no financial interest to declare in relation to the content of this article.

\section{Conflicts of interest}

There are no conflicts of interest.

\section{REFERENCES}

1. Pont LP, Marcelli S, Robustillo M, Song D, Grandes D, Martin M, et al. Immediate breast reconstruction with abdominal free flap and adjuvant radiotherapy: Evaluation of quality of life and outcomes. Plast Reconstr Surg 2017;140:681-90.

2. Parrett BM, Caterson SA, Tobias AM, Lee BT. DIEP flaps in women with abdominal scars: Are complication rates affected? Plast Reconstr Surg 2008;121:1527-31.

3. Chang CC, Huang JJ, Wu CW, Craft RO, Liem AA, Shen JH, et al. A strategic approach for DIEP flap breast reconstruction in patients with a vertical midline abdominal scar. Ann Plast Surg 2014;73 Suppl 1:S6-11.

4. Schoeller T, Wechselberger G, Roger J, Hussl H, Huemer GM. Management of infraumbilical vertical scarsinDIEP-flaps bycrossover anastomosis. J Plast Reconstr Aesthet Surg 2007;60:524-8.

5. Hsieh F, Somia N, Lam TC. A new approach to preexisting vertical midline abdominal scars with crossover DIEP flap breast reconstruction. Microsurgery 2010;30:151-5.

6. Hsieh F, Kumiponjera D, Malata CM. An algorithmic approach to abdominal flap breast reconstruction in patients with pre-existing scars - Results from a single surgeons experience Elsevier Ltd. Br J Plast Surg 2009;62:1650-60.

7. Han S, Eom JS, Kim DH. Effects of the abdominal midline incision on the survival of the TRAM flap in rat model. Ann Plast Surg. 2003; 50:171-176.

8. Dinner MI, Dowden RV, Scheflan M. Refinements in the use of the transverse abdominal Island flap for postmastectomy reconstruction. Ann Plast Surg 1983;11:362-72.

9. Sano K, Hallock GG, Rice DC. A Vertical Midline Scar Is a 'High-Risk' Factor for Maximun Survival of the Rat TRAM Flap. Ann Plast Surg. 2003; 51(4) pp. 403-408.

10. Hamdi M, Larsen M, Craggs B, Vanmierlo B, Zeltzer A. Harvesting free abdominal perforator flaps in the presence of previous upper abdominal scars. J Plast Reconstr Aesthet Surg 2014;67:219-25.

11. Wong C, Saint-Cyr M, Arbique G, Becker S, Brown S, Myers S, et al. Three-and four-dimensional computed tomography angiographic studies of commonly used abdominal flaps in breast reconstruction. Plast Reconstr Surg 2009;124:18-27.

12. Henry SL, Chang CC, Misra A, Huang JJ, Cheng MH. Inclusion of tissue beyond a midline scar in the deep inferior epigastric perforator flap. Ann Plast Surg 2011;67:251-4.

13. Santanelli F, Paolini G, Renzi L. Preliminary experience in breast reconstruction with the free vertical deep inferior epigastric perforator flap. Scand J Plast Reconstr Surg Hand Surg 2008;42:23-7. 